\title{
Electronic and Mobile Health in Chronic Heart Failure
}

\author{
An Expert Interview with Martin R Cowie \\ Imperial College London (Royal Brompton Hospital), London, UK
}

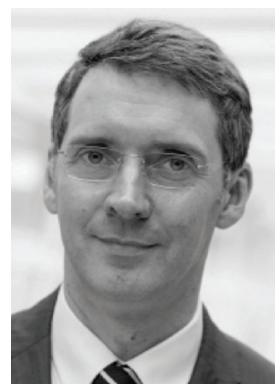

DOI: https://doi.org/10.17925/EJAE.2018.4.2.45

\begin{abstract}
Martin R Cowie
Professor Cowie is the Chair of Cardiology (Health Services Research) at the National Heart \& Lung Institute, based at Imperial College, London and an Honorary Consultant Cardiologist at the Royal Brompton and Harefield NHS Foundation Trust. He was a founding member and past-Chair of the British Society for Heart Failure, and has sat on the Board of the Heart Failure Association of the European Society of Cardiology (ESC). He is Chair of the ESC's new Digital Health Committee, responsible for co-ordinating research, educational and advocacy issues on all things digital in cardiovascular health and healthcare for the organisation. Professor Cowie has a clinical specialism in heart failure and a particular interest in electronic health (e-health) - engaging with technology to drive more effective and efficient patient care. He leads the ESC's e-health workstream, which represents over 80,000 cardiologists in more than 50 countries, and sat on the European Commission's working group on mobile health.
\end{abstract}

\section{Keywords}

Chronic heart failure, digital health, e-health, m-health, new technology

Disclosure: Martin R Cowie provides consulting advice to companies developing digital health technologies, including Servier, Boston Scientific and Abbott.

Review Process: This is an expert interview and as such, has not undergone the journal's standard peer review process.

Acknowledgements: Medical writing assistance was provided by Colin Griffin of Touch Medical Media and was supported by Touch Medical Media.

Authorship: The named author meets the International Committee of Medical Journal Editors (ICMJE) criteria for authorship of this manuscript, takes responsibility for the integrity of the work as a whole, and has given final approval for the version to be published.

open Access: This article is published under the Creative commons Attribution Noncommercial License, which permits any noncommercial use, distribution, adaptation, and reproduction provided the original author and source are given appropriate credit. (C) The Author 2018.

Received: 14 August 2018

Published Online: 7 November 2018

Citation: European Journal of Arrhythmia \& Electrophysiology. 2018;4(2):45-6

Corresponding Author: Martin Cowie, National Heart and Lung Institute, Dovehouse Street, London, SW3 $6 \mathrm{LY}$ UK E: m.cowie@imperial.ac.uk Twitter: @ProfMartinCowie

Support: No funding was received in

the publication of this article. $\mathrm{n}$ recent years, there has been increasing realisation that electronic health (e-health) - an umbrella term for multiple approaches to using information and communication technologies in health care - can encourage optimised and personalised delivery of care. ${ }^{1}$ Effective e-health initiatives may have benefits for both patient outcomes - through better education, information and self-management - and for healthcare systems - through resource sparing, data-analysis and computer-aided decision making including artificial intelligence, in remote monitoring and consultation, in both primary and secondary care. ${ }^{1-3}$ In patients with chronic heart failure, digital health technologies can enable symptom-and implanted-device monitoring, and facilitate remote patient support; importantly, patients are adherent to use of these initiatives. ${ }^{4}$ However, given the lack of standardised employment of e-health initiatives, there is a lack of awareness and understanding in the healthcare community and concern regarding data validity and security, and thus a need for education, encouragement and support to drive adoption and confident use of these technologies. ${ }^{1}$ In this expert interview, Martin Cowie discusses the current potential and regulatory issues of these technologies, and looks ahead to the future possibilities of e-health and mobile health (m-health) in chronic heart failure.

\section{Q. In brief, what is $\mathrm{m}$-health and in what specific ways can new technology (implantable devices, apps and other systems) assist the management of patients with chronic heart failure?}

M-health refers to any mobile digital technology that can be used to assist health or healthcare, but it is a term that if often used in a narrower way to refer to the use of apps (applications) on smartphones.

Remote monitoring - whether with stand-alone systems or wearables or implantables - has been used in heart failure (and arrhythmia) care for 15 years or more. Small studies or before-and-after comparisons tend to show large improvements in quality of life and reduction in risk of death or hospitalisation for patients with heart failure, but this has been more challenging to show in larger randomised trials. However, the outcomes appear at least as good as standard 'specialist' care, and using such technology can assist people to learn more about their condition and how to monitor it themselves. It also makes them feel more connected to medical or nursing support. The detection of intermittent symptomatic arrhythmia, of course, has been transformed by several m-health devices (such as Kardia [AliveCor, Mountain View, CA, US], or the Zenicor device [Zenicor Medical Systems AB, Stockholm, Sweden]), which can record a high-quality single lead electrocardiogram and then send this as a PDF (or allow this to be visible through a remote server) to the cardiologist. This, of course, has its pluses and its minuses! 
There is much research activity in this space - trying to find the right technology for the right patient at the right time.

\section{Q. Is there any regulatory oversight of the implementation and operation of e- and $\mathrm{m}$-health in chronic heart failure (or other diseases) - do any countries or health authorities have a coordinated strategy for roll-out of e- or m-health systems and subsequent monitoring of their use in chronic heart failure?}

The regulatory issues for e-health are challenging. A recent World Health Organisation survey across Europe showed little consistency between countries in terms of regulation or even guidance on such key issues as privacy and data security, value assessment, and reimbursement. 5 Attitudes do vary markedly from one country to another about data security and there are big differences in regulation between Europe and other regions of the world, particularly with the new General Data Protection Regulation in the European Union (EU) this year. So, sadly, it is difficult to find good examples of nationwide roll out of e-health or m-health; it tends to occur in a rather haphazard way, driven by local enthusiasts. But one should not forget other aspects of e-health, such as the electronic health record and electronic prescribing - that is now more or less universal in developed countries, but cross-border data transfer is still far from smooth.

\section{Q. What programs/initiatives do organisations such as the European Heart Rhythm Association and European Society of Cardiology have to help apply e- and $\mathrm{m}$-health in chronic heart failure?}

Interestingly, even silicon valley entrepreneurs now use the term 'supportive' technology rather than 'disruption', but digital transformation is here to stay. The European Society of Cardiology (ESC), and many of its associations, such as the European Heart Rhythm Association and the Heart Failure Association, are getting actively involved in this area. The ESC Board recently set up a Digital Cardiology Committee, which it is my pleasure to Chair, to ensure that initiatives move forward efficiently and that cardiologists are seen as a key stakeholder in digital changes happening across healthcare and in public health. The main ESC meeting has a 'digital space', with lots of activity and many companies presenting their new technologies and with discussion about how best to evaluate the impact of these and integrate them into day-to-day practice. A stand-alone digital meeting will take place on 4-5 October 2019 in Tallinn, Estonia, and we are looking to provide more advice and support to our members on all matters digital, including the possibly tricky area of social media. These are exciting times for healthcare professionals and professional societies.

\section{Q. In the future, is greater adoption of e- and $\mathrm{m}$-health systems in chronic heart failure likely to improve patient management and outcomes - could it also reduce doctors' workload, lower other medical resource usage and decrease costs?}

There are several forces at work here. It is certainly possible to remotely monitor a large amount of physiological data, but cardiologists fear a tsunami of information that needs to be looked at and acted upon promptly. Quite correctly, they wish good evidence that the reorganisation required to do this is worth the effort and can be financially viable for their practices and organisations. Sadly, reimbursement usually trails far behind good practice, so often healthcare providers have to modernise without strong incentives. But taking the patient perspective is important: many digital transformations (in theory at least) allow expertise to come to the patient, rather than the patient to the expertise. This means one can get high quality input wherever you live, hopefully. We need to get better at matching activity to outcome, and also to incentivise better practice that is more convenient for our patients. Many challenges lie ahead! The politicians are enthusiastic about this and the EU has allocated substantial resources to help support research and implementation in digital health. ${ }^{.}$Sadly, many politicians think anything 'digital' will be more efficient than current practice and will inevitably save money and help sustain healthcare budgets and improve citizen experience of care. Healthcare professionals are often viewed as being resistant to change: we know this is not true, but we do require good evidence for benefit.

\section{Q. E- and m-health developments have been predicted by some commentators to have the potential to 'democratise medicine' - is this likely to be the case, specifically in chronic heart failure?}

Indeed. Expertise to the patient, rather than the patient to the expertise, is key here. Digital technologies potentially widen access and should allow higher quality input at the right time and in the right place. This sounds fantastic, but the devil is in the detail. It is important to avoid the hype of a lot of press coverage; we need to get better at sorting out the good from merely the new, but where the evidence exists we should push for modernisation as strongly as we can. This needs to be a partnership between healthcare professionals, patients and their families, society in general, industry and regulators/reimbursement authorities. The ESC and its associations will be ever more involved in this process. $\square$
1. Cowie MR, Bax J, Bruining N, et al. E-health: a position statement of the European Society of Cardiology. Eur Heart J. 2016;37:63-6.

2. Hall AK, Dodd V, Harris A, et al. Heart failure patients' perceptions and use of technology to manage disease symptoms. Telemed J E Health. 2014;20:324-31.

3. Talboom-Kamp EP, Verdijk NA, Harmans LM, et al. An eHealth platform to manage chronic disease in primary care: An innovative approach. Interact J Med Res. 2016;5:e5.

4. Piotrowicz E. The management of patients with chronic heart failure: the growing role of e-health. Expert Rev Med Devices. 2017; 14:271-7

5. World Health Organization Regional Office for Europe. From innovation to implementation: eHealth in the WHO European Region. 2016. Available at: www.euro.who.
int/_data/assets/pdf_file/0012/302331/From-Innovation-toImplementation-eHealth-Report-EU.pdf?ua=1 (accessed 4 September 2018).

6. European Commission. New Digital Europe Programme brings $€ 9.2$ billion investment between 2021-2027. 2018. Available at: https://ec.europa.eu/isa2/news/european-commission-hasannounced-investment-\%E2\%82\%AC92-billion-align-next-longterm-eubudget-2021 en (accessed 8 October 2018). 